\title{
Kristian Birkeland's pioneering investigations of geomagnetic disturbances
}

\author{
A. Egeland ${ }^{1}$ and W. J. Burke ${ }^{2}$ \\ ${ }^{1}$ University of Oslo, Norway \\ ${ }^{2}$ Air Force Research Laboratory, USA
}

Received: 11 February 2010 - Accepted: 15 March 2010 - Published: 12 April 2010

\begin{abstract}
More than 100 years ago Kristian Birkeland (1967-1917) addressed questions that had vexed scientists for centuries. Why do auroras appear overhead while the Earth's magnetic field is disturbed? Are magnetic storms on Earth related to disturbances on the Sun? To answer these questions Birkeland devised terrella simulations, led coordinated campaigns in the Arctic wilderness, and then interpreted his results in the light of Maxwell's synthesis of laws governing electricity and magnetism. After analyzing thousands of magnetograms, he divided disturbances into 3 categories:
\end{abstract}

1. Polar elementary storms are auroral-latitude disturbances now called substorms.

2. Equatorial perturbations correspond to initial and main phases of magnetic storms.

3. Cyclo-median perturbations reflect enhanced solar-quiet currents on the dayside.

He published the first two-cell pattern of electric currents in Earth's upper atmosphere, nearly 30 years before the ionosphere was identified as a separate entity. Birkeland's most enduring contribution toward understanding geomagnetic disturbances flowed from his recognition that field-aligned currents must connect the upper atmosphere with generators in distant space. The existence of field-aligned currents was vigorously debated among scientists for more than 50 years. Birkeland's conjecture profoundly affects present-day understanding of auroral phenomena and global electrodynamics. In 1896, four years after Lord Kelvin rejected suggestions that matter passes between the Sun and Earth, and two years before the electron was discovered, Birkeland proposed current carriers are "electric corpuscles from the Sun" and "the auroras are formed by corpuscular rays drawn in from space, and coming from the Sun". It can be reasonably argued that the year 1896 marks the founding of space plasma physics. Many of Birkeland's insights were rooted in observations made during his terrella experiments, the first attempts to simulate cosmic phenomena within a laboratory. Birkeland's ideas were often misinterpreted or dismissed, but were verified when technology advances allowed instrumented spacecraft to fly in space above the ionosphere.

\section{A brief biography}

Olaf Kristian Bernhard Birkeland was born in Kristiania, the capital of Norway, on 13 December 1867 and died in Tokyo on 15 June 1917. The capital's name reverted to Oslo in 1925 , three centuries after it was devastated by fire. He was appointed professor of physics at The Royal Frederik University in Kristiania near the end of the 19th century. In publi- cations after 1898 he simply referred to himself as Kr. Birkeland. His life spans a watershed period when insights about electricity and magnetism, codified by Maxwell in the mid19th century, evolved from theoretical curiosities to become the basis for modern electronic technology as well as our understanding of the geospace environment. Here we summarize his pioneering studies of magnetic disturbances and relate them to present-day space research. 

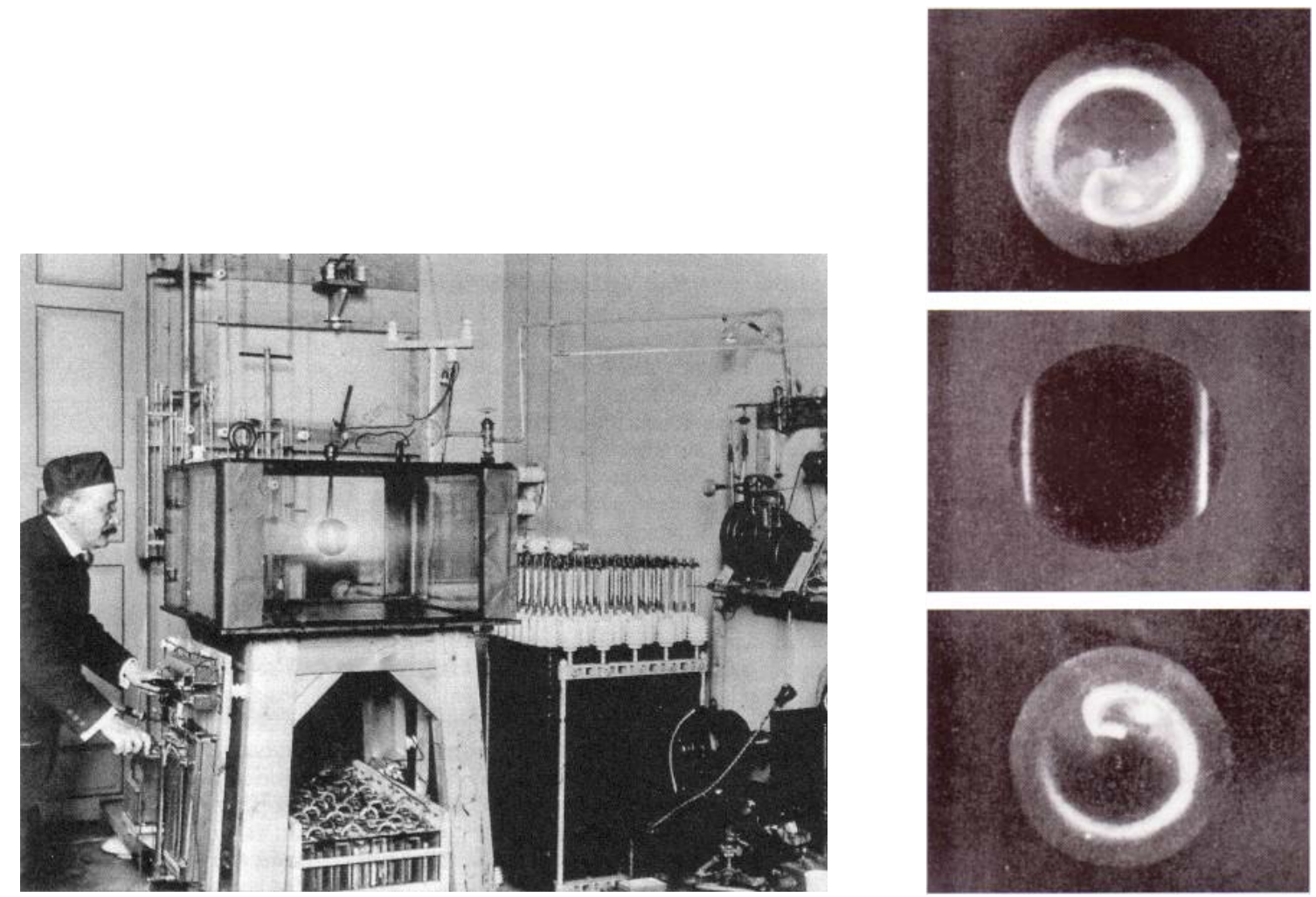

Figure 1. Kristian Birkeland (ca. 1910) standing at the controls of a terrella while conducting solar-terrestrial simulations. The photograph on the right shows a terrella experiment that reproduced the locations of the auroral zones as well as the spiral-shaped forms at both poles. Noticed that the auroral forms at the Northern and Southern Hemisphere curl in different directions (Birkeland, 1908, p. 327 and Birkeland, 1913, p. 712-713).

As a young student Birkeland showed a keen interest in both mathematics and physical science. He completed university studies in physics in June 1890, youngest in his class and with the highest grades. Much of his early research was conducted in France and Germany between January 1893 and August 1895. His mathematical training provided a superb foundation for developing the first general solution of Maxwell's equations and energy transfer by means of electromagnetic waves (Birkeland, 1895). He continued to investigate the properties of electromagnetic waves in conductors and wave propagation through space. From 1895 to 1917 his scientific research focused on geomagnetic disturbances, auroras, solar-terrestrial relations and cosmology. Birkeland was gifted with a wonderfully inventive mind that bubbled with ideas and sought to investigate any and all aspects of the physical sciences (Egeland and Burke, 2005). Birkeland's main work regarding auroras and geomagnetic disturbances is summarized in "The Norwegian Aurora Polaris Expedition 1902-1903". This 801-page monograph consists of two volumes that were published separately. Volume I (Birkeland, 1908) covers pages 1 to 316; volume 2 (Birkeland, 1913) covers pages 317 to 801 . In this monograph related citations are to NAPE with page number(s).
From 1903 to 1906 Birkeland diverted much of his attention toward applied physics and technological development. His motive for engaging in such activities was to generate the funds he needed to support his research projects and to build a modern research laboratory whose cost greatly exceeded what the University's budget could afford. Birkeland eventually held sixty patents in ten different subject areas. In one field, the production of agricultural fertilizers, he earned large sums of money. He invented the plasma arc which led to the Birkeland-Eyde method for industrial nitrogen fixation for synthesizing artificial fertilizers and then to the founding of Norsk Hydro which is still among Norway's largest industrial enterprises. Eight nominations for the Nobel Prize, divided equally between chemistry and physics, attest to the high esteem with which contemporary scientists regarded Kristian Birkeland. 


\section{Prior investigations of the Earth's magnetic field}

For many centuries the magnetic properties of lodestones and magnetite were known and used as navigational aids. William Gilbert (1544-1603) conducted the first systematic investigation of the Earth's magnetic field and in1600 published the results in "De Magnete". His most important conclusion was that "the Earth itself is a large magnet". Scientists long recognized that the Earth's magnetic field changes continuously and often violently (e.g. Gauss, 1841; Chapman and Bartels, 1940). In 1716 Edmund Halley (16561742) found a correlation between the occurrences of geomagnetic disturbances and visible auroras. In $1741 \mathrm{An}$ ders Celsius (1701-1744) and Olaf Peter Hiorter (16961750) noticed that the orientation of a suspended magnetic needle tilted either to the left or right of magnetic north whenever auroral lights were visible. More than a century would pass before Birkeland proposed the first scientifically correct explanation of this mysterious relationship. He argued that fluctuations of the geomagnetic field provide critical information about electrical currents flowing in space above the Earth. In 1820 Hans Christian Ørsted (17771851) demonstrated that electric currents cause magnetic disturbances. Later Michael Faraday (1791-1867) would show that time-varying magnetic fields induce electric currents. James Clerk Maxwell (1831-1879) unified the work of Ørsted and Faraday, consolidating them into the four fundamental laws of electromagnetism. Starting in 1814 Christofer Hansteen (1774-1873) was the first professor at the University of Kristiania to study geomagnetism. To support his studies Hansteen built several instruments to measure the magnetic field's strength and declination. A magnetic map he derived during an expedition (1829-1830) across Siberia provided critical new information about the field's global structure.

Systematic recordings of simultaneous geomagnetic field variations over wide regions began in 1834, when Carl Friedrich Gauss (1777-1855) first deployed magnetometers of the Gøttingen Magnetic Union at stations across Europe. Gauss' "Algemeine Theorie des Erdmagnetismus" initiated the modern study of geomagnetism by adapting the gravitation potential theory of Pierre-Simon Laplace (17491827 ) to the Earth's magnetic field (Gauss, 1841). He regarded the total field $(B)$ as being generated by two current sources that flow within the Earth $\left(B_{\text {int }}\right)$ and somewhere above it $\left(B_{\text {ext }}\right)$. To a first approximation, $B_{\text {int }}$ can be represented as a magnetic dipole. Externally generated fields are much weaker than $B_{\text {int }}$. $B_{\text {ext }}$ varies from $\sim 50 \mathrm{nT}$ on quiet days to $>3000 \mathrm{nT}$ at auroral latitudes during magnetic storms. While the existence of large and variable currents was recognized, their distributions and causes remained obscure. Following the discovery of cathode rays, Eugen Goldstein (1850-1930) suggested the possibility that electric currents might flow out of the Sun. In 1882, the Scottish physicist Balfour Stewart (1828-1887) argued that electric currents also flow in the layers of the tenuous upper atmosphere now called the ionosphere. Birkeland's investigations responded to both suggestions.

\section{Terrella simulations}

Dessler (1983) described Birkeland as a complete scientist, a gifted mathematician and theorist, as well as an imaginative laboratory and field experimentalist. Birkeland devised laboratory experiments that, for their time, were of unprecedented size and complexity, and he made them work. While a professor of physics at the University of Kristiania, Birkeland initiated a set of laboratory simulations that he referred to as terrella experiments. He hoped to use his terrellas as tools for understanding the sources of auroral and geomagnetic disturbances. For the first time cosmic phenomena were scaled and simulated in a laboratory. These experiments were at once simple and ingenious. His largest chamber occupied a full cubic meter. These laboratory simulations first suggested that energetic particles from the Sun were direct causes of auroras. It is well known that Birkeland used energetic electron beams in his terrella experiment, causing some to think that he regarded the Sun as a cathode-ray source (Schuster, 1911). Although Birkeland often focused on negatively charged particles because of their role in exciting auroral emissions, he stated on a number of occasions that, "Corpuscular beams from the Sun contain both electrons and positive ions." Birkeland also wrote: "From a physical point of view it is most probable that solar rays are neither negative nor positive rays, but of both kinds" (Birkeland, 1916). Qualitatively, Birkeland's image of combined beams from the Sun is quite compatible with present understanding of the solar wind.

Terrella experiments also opened new paths suggesting how electromagnetic forces might operate in the solar system. Birkeland's laboratory simulations were brilliant successes that allowed him to argue by analogy about the causes of auroras and geomagnetic disturbances. After 1906, Birkeland extended his terrella experiments and applied the electromagnetic theory to include solar and planetary phenomena. His approach generated fruitful frameworks for understanding basic plasma processes. Much of Birkeland's story concerns hard won observations and bold interpretations of the natural interactions between the Sun and the Earth's magnetic field that produce auroral displays and geomagnetic storms. He distinguished himself from contemporary investigators though laboratory simulations of natural electrical phenomena. Birkeland's concepts about the electric particles and currents controlling the physics of space were far ahead of his time. Birkeland based the main part of the physical interpretation on laboratory simulations and daring campaigns in the Arctic wilderness, interpreted in the light of Maxwell's laws of electricity and magnetism. His insightful interpretation of solar-terrestrial interactions remains central to this field. 


\section{Arctic expeditions}

Birkeland conducted three auroral and geomagnetic field expeditions between 1897 and 1903. Of these, his four-station polar expedition during the winter of 1902-1903 was the most significant (Alfvén and Egeland, 1987). Birkeland's first expedition in 1897 was a disaster. He planned to build an observing station near $70^{\circ} \mathrm{N}$ in Finnmark, Norway's northernmost province. Soon after reaching the selected site at Altafjord, his team encountered an early, but severe snowstorm in which the temperature fell to $-25^{\circ} \mathrm{C}$. They barely survived a full day and night of exposure. Birkeland later reported, "The storm increased with frightful rapidity. All had frostbitten noses and chins, but nothing could be done. We could see nothing and could not walk. Everyone had to get into his sleeping bag as quickly as possible.” They struggled back to their starting point $31 \mathrm{~h}$ later.

In the fall of 1899 Birkeland returned to Finnmark to resume auroral and magnetic observations. In preparation for this second expedition during the winter of 1899-1900, a permanent observatory was built on the summit of Haldde Mountain, a rocky peak with steep slopes. To triangulate auroral heights a second station was built on Talvik Mountain about $3.4 \mathrm{~km}$ away. Haldde and Talvik are more than $900 \mathrm{~m}$ high and located to the west of Altafjord. Observation cycles were coordinated by telephone. The walls of both observatories were made of fieldstone nearly a meter thick. The roofs were layered timbers of sturdy Norwegian design. Even in these sturdy structures, the isolation and vulnerability his teams endured while wintering at these stations is almost unimaginable. Birkeland reported that several times during winter storms wind speeds exceeded $46 \mathrm{~m} / \mathrm{s}$, the highest the anemometer could measure. The lowest temperature reached was $-34^{\circ} \mathrm{C}$. He was proud of his small, sturdy observatories at perfect sites for studying the high-latitude sky with views unhampered by artificial lights, trees, or buildings. Tragically, one of Birkeland's young student assistants, Elisar Boye, was lost in an avalanche late in the campaign. Birkeland's book describing the campaign, "L'Expédition Norvégienne de 1899-1900 pour l'étude des Auroras Boréales: Resultats des Recherches Magnetiques", is dedicated to the memory of Boye.

In 1901 Birkeland began planning a comprehensive expedition with four stations about $1000 \mathrm{~km}$ apart at high latitudes. The 1902-1903 expedition is well documented in the NAPE publications of 1908 and 1913. His four stations (see Fig. 2) were at: (1) Kåfjord, in Finnmark, near the Haldde Observatory, (2) Dyrafjord, in Iceland, (3) Axeløen in the Svalbard Archipelago, and (4) Matotchkin Schar on Novaya Zemlya, Russia. These stations and the distances between them are marked on Birkeland's original map shown below. These sites required scientists with experience living in harsh arctic environments. Thus, each team was required to include at least one scientist who had wintered at an arctic station. This expedition was scientifically very successful.

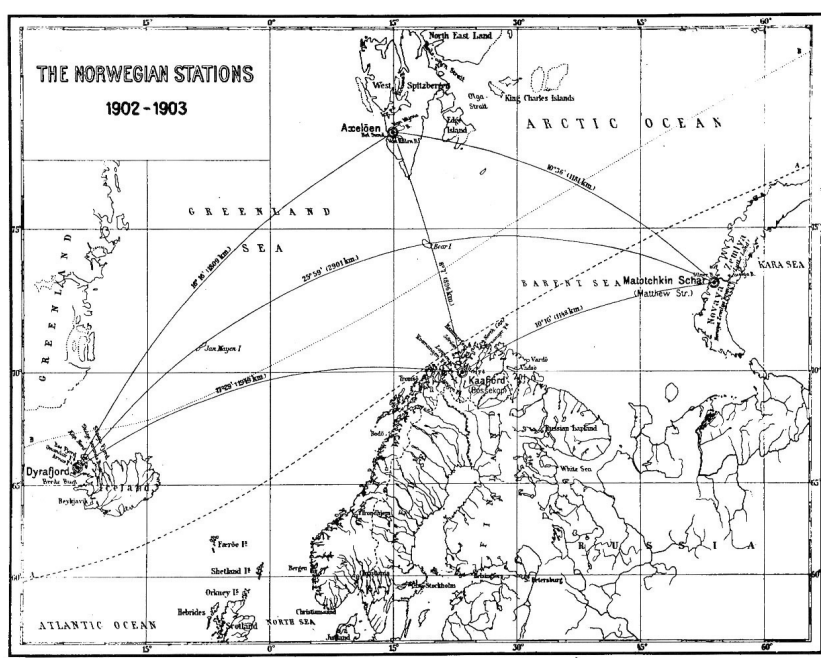

Figure 2. Map showing locations of the four auroral observatories established in 1902 to chart variations in the Earth's magnetic field. The stations were each separated by about $1000 \mathrm{~km}$ (Birkeland, 1908).

\section{Disturbance classification}

Birkeland analyzed thousands of magnetic records from around the world. For several events during the winter of 1902-1903 he had access to simultaneous recordings from 30 different observatories. From The First Polar Year 18821883 he had data from 15 stations. This analysis led him to divide magnetic disturbances into three categories with welldefined characteristics (NAPE, p. 430-437):

\section{Polar elementary storms}

\section{Equatorial perturbations}

\section{Cyclo-median storms}

Birkeland's original descriptions of these three classes of elementary disturbances are quoted in the famous textbook "Geomagnetism"(Chapman and Bartels, 1940, p. 317-326). One of Birkeland's great scientific strengths was a keen eye for perceiving characteristic patterns in data and rapidly drawing hypotheses that through more detailed analyses he either could confirm or reject. He also had a remarkable ability to see parallels between laboratory and field experiments, often pointing out, "To a large extent I based my conclusions on simulation experiments in the laboratory".

\subsection{Polar elementary storms}

"Negative and positive polar perturbations rarely occur alone. As a rule they occur simultaneously, but in different districts. It appears that, on the whole, they are grouped in the same manner with respect to the Sun (NAPE, p. 445)". 
In Birkeland's view these positive/negative types of disturbances had "a certain genetic connection". Polar elementary storms, which are closely connected with the generation of auroras, were first identified during the Haldde expedition. Consequently, further understanding demanded coordinated observations to complement measurements from a single station. Polar elementary storms are now referred to as "substorms" although Birkeland's nomenclature appears more logical. In the 1960s, Sydney Chapman (1888-1970) was asked to name disturbance types, and his assigned name "substorm" prevailed.

On the maps Birkeland located the most intense overhead currents at the latitudes and longitudes of the stations recording the most intense magnetic disturbances. According to Birkeland, the disturbance fields of polar elementary storms are produced by strong horizontal currents that flow in the auroral zone. They are connected to field-aligned currents that flow into and out of the upper atmosphere from both edges of the horizontal auroral-zone currents. Figure $3 \mathrm{~b}$ shows Birkeland's representation of the current system.

\subsection{Equatorial perturbations}

Positive and negative magnetic disturbances of the horizontal component of the Earth's magnetic field at low latitudes correspond to the initial and main phases of magnetic storms. According to Birkeland (NAPE, p. 439-440): "The deflections in horizontal intensity always increase at the beginning of the storm rather rapidly and to a certain height, after which the perturbing forces remain more or less constant in strength for a long period (say up to $6 \mathrm{~h}$ ). In the horizontal-intensity curve, there are always a number of very characteristic variations, that are found again at all the stations situated in low and medium latitudes, and these variations appear at any rate nearly simultaneously all over the globe."

"The negative equatorial storms are more powerful in the region of the equator, where the perturbing forces in horizontal intensity are negative. The forces that occur in the negative equatorial storms are also considerably greater than those found in the positive. Among our observations we have found only examples of negative equatorial storms, which occur simultaneously with polar storms, and it is perhaps doubtful whether this type of perturbation on the whole can occur alone. We have insufficient material, however, for the formation of any well-founded opinion on the matter" (NAPE, p. 447).

Two objectives of the 1902-1903 Polar Expedition were to identify periodicities in the occurrences of polar storms and to determine time delays between the meridional passage of sunspots and the onset of magnetic disturbances. Birkeland felt quite certain that the Sun was the source of great storms. However, data from his stations showed that disturbances recurred on average in 29.1 days, more than a day longer than expected based on existing knowledge of the Sun's 28-day rotation. This puzzled Birkeland. Was it pos- sible the difference was simply an artifact of his analysis? He knew of no geophysical cause. It was clear that some storms were associated with the meridional passage of large sunspot groups. In these cases, a storm began on average 1.6 days later, corresponding to an average speed of $1080 \mathrm{~km} / \mathrm{s}$ for the "agent" causing the disturbance. According to Birkeland, these observations showed "that the appearance of large sunspot groups does not take place as regularly as the principal maxima of storminess" and "very often large storms are not accompanied by any sunspots at all." These facts led Birkeland to conclude, "Regarding the connection between sunspots and storminess it seems improbable that sunspots can be the direct cause of magnetic storms. ... The results suggest that sunspots and magnetic storms are both manifestations of the same primary cause." Birkeland felt that the main source had to emit corpuscles continuously, even when the region faced away from Earth (NAPE, p. 526, 614). He used the phrase "pencil rays" to describe the likely source of geomagnetic storms. Birkeland's 1902-1903 campaign was conducted near sunspot minimum. We now know that highspeed streams from coronal holes, invisible from the ground, are the probable causes of periodic storms. We also know that Birkeland observed seasonal and latitudinal effects of the Sun's rotation, which is slower at mid-latitudes than at the equator.

\subsection{Cyclo-median perturbations}

As their name suggests, the third type of magnetic perturbations primarily occurs at dayside mid-latitudes. The observed magnetic perturbations result from closed (nearly circular) current loops of limited size flowing not far above the Earth. Viewed from above in the Northern Hemisphere, current flows in the counter-clockwise sense. Unlike auroral currents, the new ionization cannot be created by the impact of energetic charged particles. Rather this type of disturbance is associated with the occurrence of solar flares. Intensifications of ultraviolet light from the Sun increase the density of ionospheric plasma and thus the amount of current they can carry. Birkeland was first to recognize this distinctive type of variation in the Earth's magnetic field.

\section{Upper atmospheric electric current systems}

Birkeland's most enduring contribution to solar-terrestrial research was his recognition that field-aligned currents are needed to couple geomagnetic and auroral phenomena in the upper atmosphere to interplanetary space and the Sun. Considering his early work with Maxwell's equations and his laboratory simulations, it is not surprising that in 1899 Birkeland was already convinced that electric currents flowing in the upper atmosphere must be the main cause for the observed geomagnetic disturbances. His analysis of magnetic records discussed in "Résultats des recherches magnéthiques 


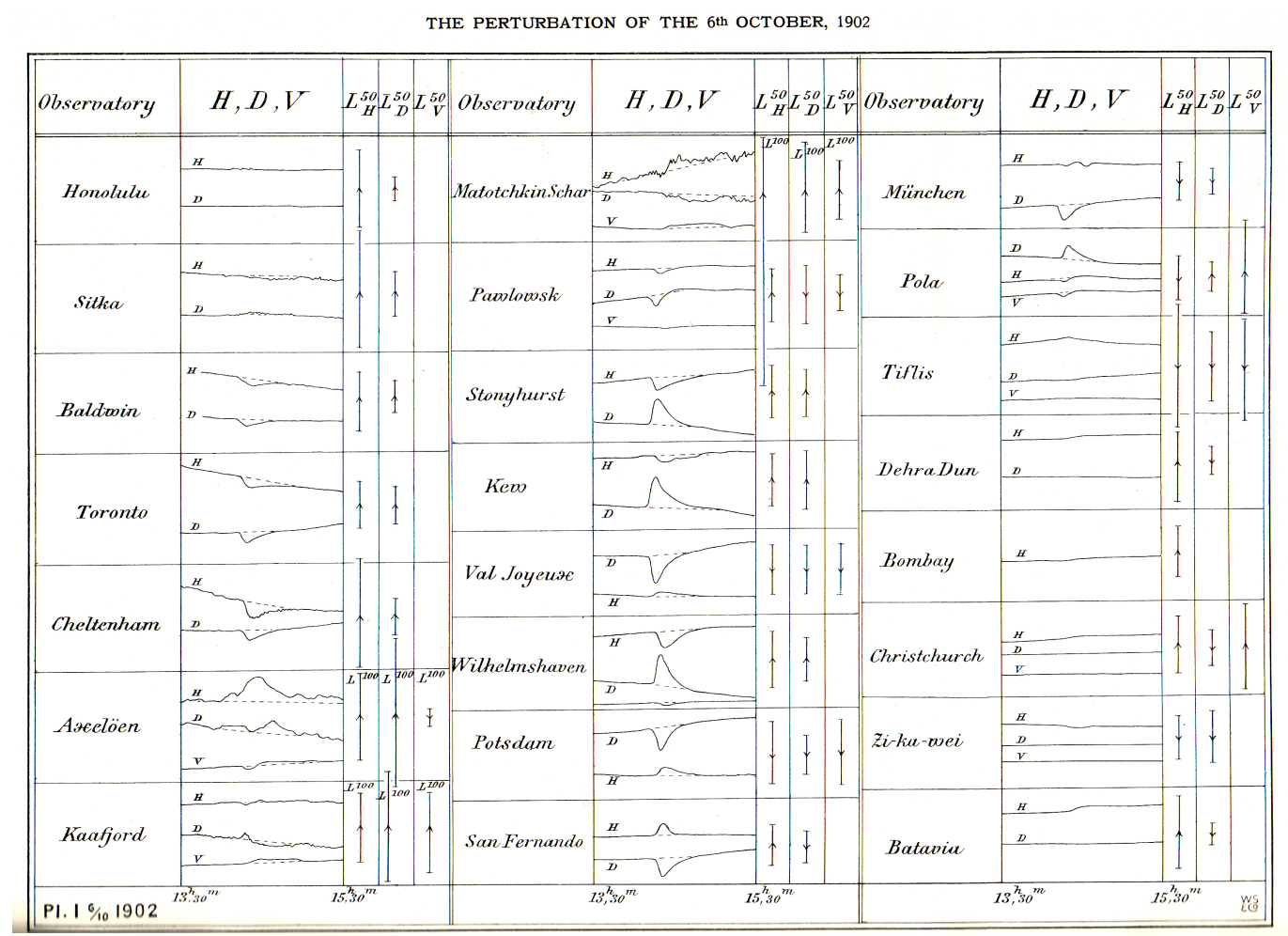

Figure 3a. A collection of magnetic records acquired on 6 October 1902 (NAPE, Pl. I) illustrates the quality and quantity of magnetic stations available to Birkeland.

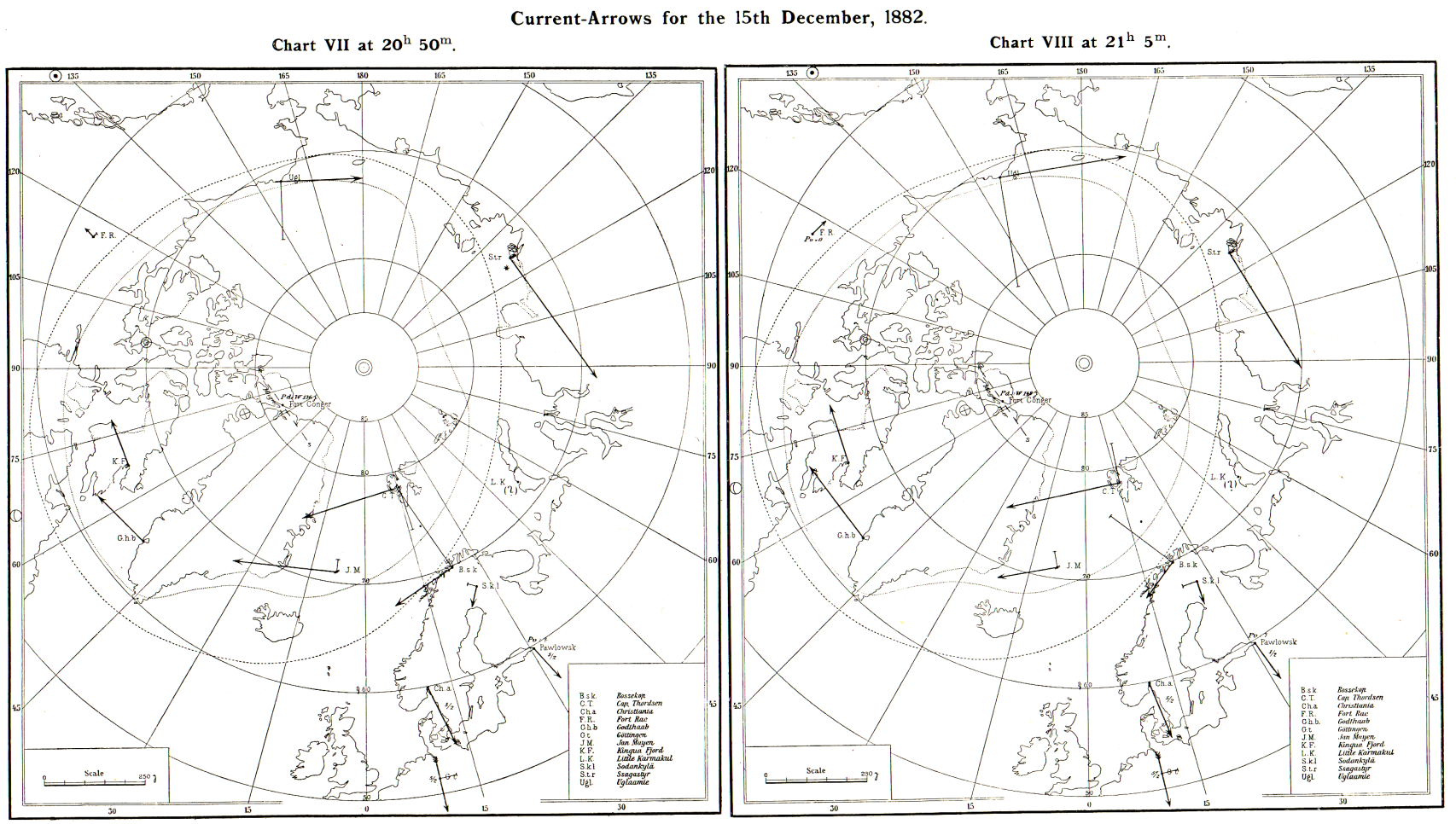

Figure 3b. Birkeland represented sources of magnetic disturbances as equivalent currents flowing overhead and represented by arrows drawn on world maps (NAPE, Vol. I). 


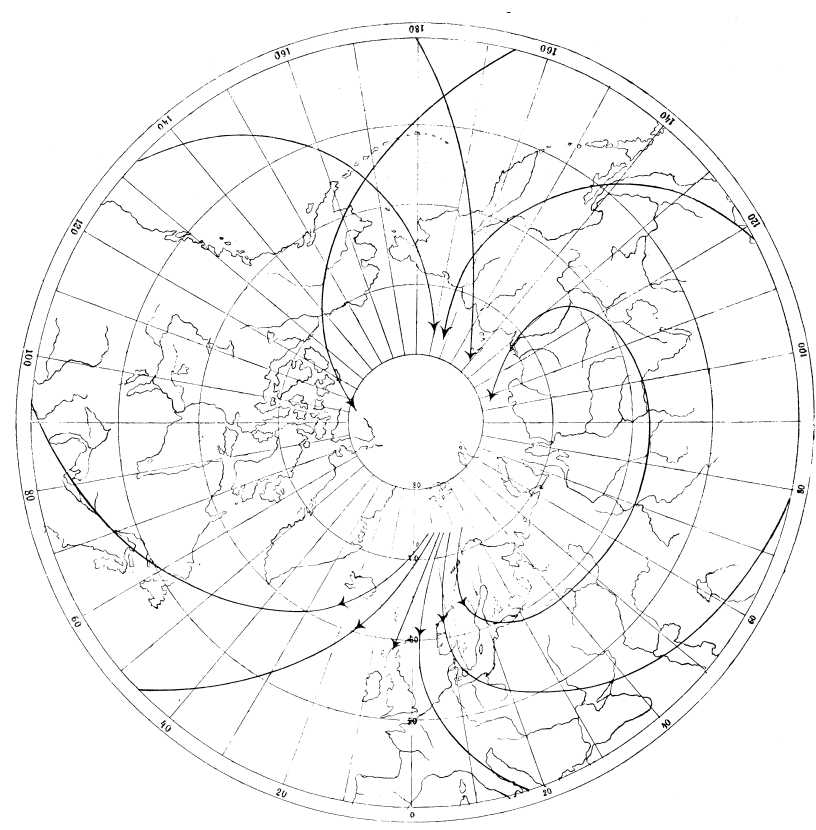

Figure 4. Current patterns viewed from above the North Pole. Birkeland called the drawn curves "lines of currents at midnight, Greenwich time". The global ionospheric currents are represented in a coordinate system oriented with respect to the Sun. In a 24-h period, the Earth rotates under the current pattern, as indicated by the curved lines (Birkeland, 1901).

faites par l'expédition Norvégienne de 1899-1900" (Birkeland, 1901) led to global maps marked by symbols for the intensities and directions of currents responsible for perturbations. He clearly recognized that the magnetic perturbations were at right angles to their causative currents. It was from this type of analysis that he discovered the strong east-west auroral "electrojets" with currents up to a million Amperes (Birkeland, 1901). He argued that terrestrial phenomena associated with auroral emissions are best described in a coordinate system that is fixed with respect to the Sun. He then constructed the first "two-cell global pattern" of atmospheric currents that converge over the polar region based on ground magnetic field measurements. Modern satellite-based measurements of electric fields confirm the existence of the twocell patterns and are critical for understanding how energy from the Sun disturbs the high-latitude ionosphere.

Today Birkeland's upper atmosphere is called the "ionosphere". More than two decades would pass before Appleton identified the ionosphere as a distinct part of the atmosphere. About three years after Thomson (1897) identified electrons as independent and fundamental units of charge, Birkeland understood that upper atmospheric currents could derive energy from two possible sources. In NAPE (Sect. 36) he wrote: "With regard to the future course of the current, there are two possibilities:
1. "The entire current system belongs to the Earth. The current-lines ... flow at some height above the Earth."

2. "The current is maintained by a constant supply of electricity from without. The currents will $\mathrm{c}$ onsist principally of vertical portions. At some distance from the Earth's surface, the current from above will turn and continue for some time in an almost horizontal direction, and then either once more leave the Earth, or become partially absorbed by the atmosphere."

Birkeland's explanation of polar elementary storms favored field-aligned currents as is clearly expressed in NAPE (Sect. 92) where he wrote: "We consider it to be beyond doubt that the powerful storms in the northern regions, that we have called elementary, are due to the action of electric currents near the auroral zone". Thus, strong currents flowing overhead in the auroral zone produced the observed magnetic disturbances. The important new point for Birkeland was that the horizontal currents connect to currents flowing along the Earth's magnetic field into and out of the upper atmosphere near the equatorward and poleward boundaries of the auroral electrojet. Some of Birkeland's original sketches of field-aligned current explanations of the negative polar elementary storms, published in the section of NAPE (Vol. 1, Sect. 1) called "On the cause of magnetic storms and the origin of terrestrial magnetism", are shown in Fig. 5.

As the first to examine disturbance records from around the globe during magnetic storms, Birkeland estimated that currents up to one million Amperes (MA) must flow in the upper atmosphere. He understood intuitively that only the Sun could drive and sustain such large electrical currents. Consequently, currents in the upper atmosphere must connect to generators in deep space via magnetically fieldaligned currents. Indeed, Birkeland found the predicted currents replicated in laboratory simulations. He estimated that horizontal currents flowed at altitudes above $100 \mathrm{~km}$. These conjectures fit well with present day estimates that the auroral electrojet ranges between 0.3 and $5 \mathrm{MA}$. Given the intensity of currents needed to explain observed magnetic disturbances, Birkeland concluded that only the Sun could provide the electromagnetic forces needed to power magnetic storms and auroral emissions. His conclusion that field-aligned currents couple geomagnetic phenomena to interplanetary space has profound and far-reaching significance for understanding the origin of auroras and geomagnetic currents. Direct evidence for the existence of field-aligned currents was not established until 1966 with measurements from a magnetometer onboard a US Navy TRIAD satellite (Potemra, 1989). A year later the International Union for Geomagnetism and Aeronomy declared that they should be called "Birkeland currents". 


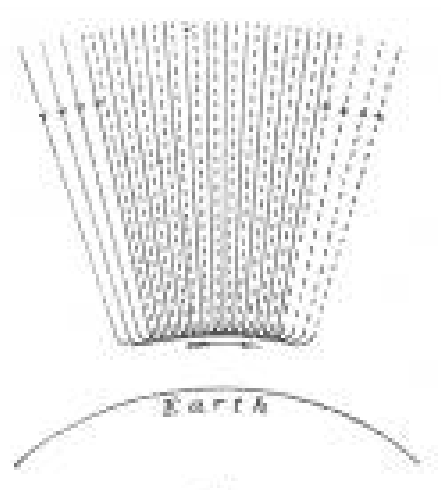

a.

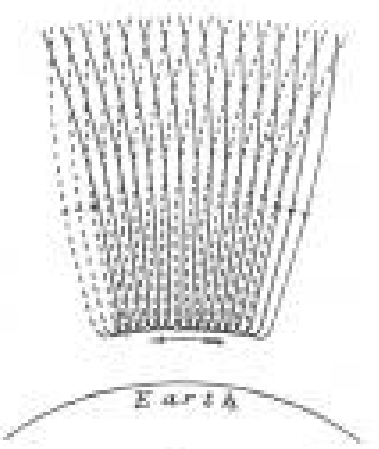

6.

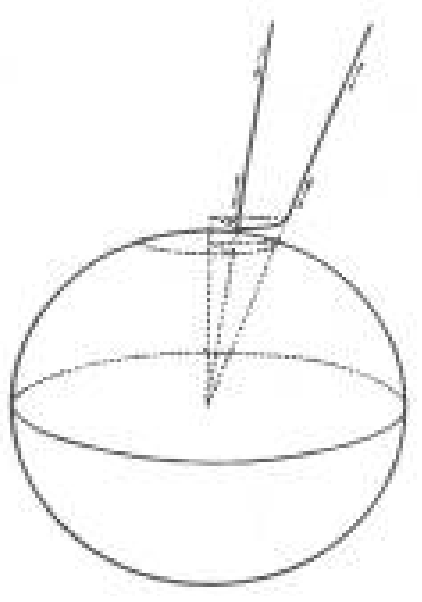

Figure 5. Original system of field-aligned currents proposed by Birkeland in the NAPE chapter "On the Cause of Magnetic Storms and the Origin of Terrestrial Magnetism" (Birkeland, 1908, Vol. 1).

\section{Field-aligned current controversies}

The presence of currents in the polar ionosphere is most commonly detected through the magnetic perturbations they produce on the ground. The existence of field-aligned currents was disputed vigorously among scientists for more than 50 years. British scientists (collectively referred to as the British School) headed by the eminent mathematician and scientist Sydney Chapman (1888-1970) were critical of
Birkeland's work in general, and in particular of his conjecture about field-aligned current. They argued that disturbances observed with ground magnetometers could be explained by "equivalent" current patterns that completely close within the ionosphere. In Chapman's view fieldaligned currents were superfluous (Chapman, 1968).

Even before Chapman entered the field of geomagnetism in 1918, British scientists paid scant attention to Birkeland's analysis of geomagnetic disturbances. They found it impossible to believe that the Sun could be the source of auroral and geomagnetic activity. In 1892 William Thomson (18241907), known as Lord Kelvin, expressed an opinion that no matter passes between the Sun and the Earth. In spite of mounting evidence to the contrary, Kelvin's opinion would only be rejected definitively after satellites had passed beyond the Earth's magnetic field into the solar wind. Although, Birkeland was aware of these objections, he found terrella simulations of auroras so compelling that he stood by his hypothesis calling for direct impacts by solar particles.

Chapman introduced a number of important theoretical concepts into contemporary magnetospheric and ionospheric physics. He approximated the overhead currents as flowing horizontally in the ionosphere and from this perspective diligently denounced Birkeland's ideas. His methodology was distinctly different from Birkeland's. Instead of focusing on individual events, Chapman and colleagues sought to identify average morphologies of magnetic disturbances from their statistical means, an approach that emphasizes communality. They concluded that magnetic variations observed during large storms differ in magnitude but not in form from their quiet-time counterparts. Their thinking dominated magnetic storm studies up to the space age and argued that the current system Birkeland proposed is inadequate and even contradictory (Vestine and Chapman, 1938). Chapman argued that the equivalent-current system method explained all observations claiming: "Birkeland's current system should be disregarded as unsatisfactory."

Representing the pro-Birkeland opposition to the British school were Hannes Alfvén (1908-1989), the 1971 Nobel Laureate in Physics and Alexander J. Dessler of Rice University. Both greatly admired Birkeland's work becoming his unyielding champions and, along with several Japanese scientists, argued strongly for the necessity of field-aligned currents for understanding magnetic disturbances and auroras. Reflecting on the impasse in 1964, Naoshi Fukushima (1920-2003) undertook a serious review of the positions of both sides. He made two critical discoveries. First, he found that Vestine and Chapman (1938) had unintentionally misrepresented Birkeland's concept of field- aligned currents. Second, a quirk of nature makes it impossible using only ground-based magnetic field measurements to distinguish unambiguously between current systems that contain field-aligned segments and those that completely close in the ionosphere. Chapman's and Birkeland's system of currents produce exactly the same magnetic perturbations when 

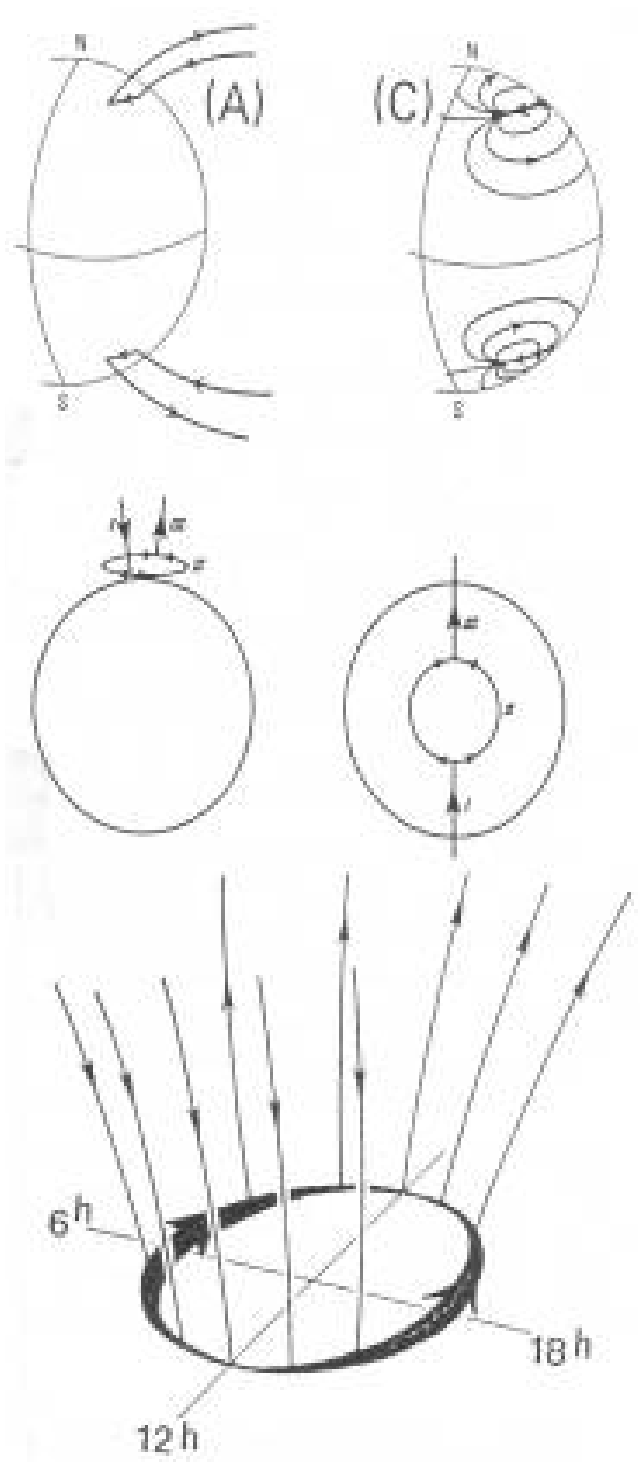

Figure 6. The current system developed by Chapman (C) and Birkeland (A). The two middle curves illustrate the model the British school used to reject Birkeland's idea, while they should have used the one shown at the bottom - the one Birkeland proposed (Fukushima, 1989).

measured at ground level (Fukushima, 1969). Determining the operative current structure required magnetic field measurements in space.

In retrospect both the detection and identification of magnetic perturbations caused by field-aligned currents appears more straightforward than anyone at that time expected. However, they could only be detected using magnetometers on spacecraft flying above the horizontal current layers in the ionosphere.

In the first decade of the 20th century Birkeland reached truly innovative conclusions about the physics underlying the aurora and geomagnetic disturbances. The British School shared neither Birkeland's intuition nor his trust in laboratory simulations and felt they could explain magnetic perturbations observed on the ground as resulting from a system of equivalent currents flowing in the upper atmosphere. Scientists are human beings who may feel loyalties that blind them to new understandings expressed in unfamiliar words. During The Birkeland Symposium in 1967 attendees unanimously proposed that field-aligned currents in space should henceforth be called "Birkeland currents". This recommendation was later ratified by the International Union for Geomagnetism and Aeronomy.

\section{Field-aligned currents in the space age}

During the space age, many papers based on mathematical models and simulations regarding associated threedimensional currents have been published (e.g. Bostrøm, 1968). From energy considerations Vasyliunas (1970) demonstrated that equivalent ionospheric currents cannot be sustained without field-aligned currents. However, as we have seen absolute poof for the existence of field-aligned currents can only come from satellite measurements taken above the ionosphere. In the mid-1960s a three-axis vector magnetometer on the TRIAD satellite provided the first direct measurements of magnetic perturbations due to field aligned currents. Interestingly, it took more than a little persuasion to convince the principal investigator and his team that they had in fact crossed sheets of field-aligned currents (Dessler, 1983). In a series of papers Iijima and Potemra $(1976,1978)$ used statistical inference to demonstrate the existence of a globally distributed, large-scale network of fieldaligned currents that is nearly co-terminal with the auroral oval. In crossing field-aligned currents, magnetometers on polar-orbiting satellites routinely detect characteristic shears in the local magnetic field. Single-satellite measurements only provide information about the distribution of Birkeland currents near its orbital plane at the moment of transit. It takes multiple spacecraft to specify their global distribution at that time. Such a capability now appears to be within reach. Anderson et al. (2000) argued that the polar-orbiting satellites of the Iridium constellation can provide this capability.

Field-aligned currents have far-reaching significance for understanding how the ionosphere couples to energy sources in the magnetosphere and the solar wind. Many observations of Birkeland currents and their association with magnetic disturbances have been reported in recent decades. Patterns of such large-scale currents deduced from satellite measurements are also supported by observations of electric fields and auroral particles. Birkeland currents are critical for understanding electrical coupling between the magnetosphere and the auroral ionosphere. Global intensities can reach several million Amperes. The energy they dissipate in the upper atmosphere greatly exceed that deposited by electrons and 
ions that cause intense aurora displays. Today, many plasma physicists are convinced that many phenomena such as:

1. Auroral arcs, rays and bands,

2. Auroral electrojets,

3. Inverted-V structures in auroral particle precipitation, and

\section{Flux ropes in the solar wind}

are caused by field-aligned currents (Egeland and Burke, 2005). Birkeland currents are probably involved in other phenomena in the plasma universe. Peratt (1996) suggested that pinched Birkeland currents may even trigger the gravitational collapse of matter in the plasma state.

\section{Geomagnetic disturbances research in the space age}

On the nights of 9 and 10 September 1898 dazzling auroral displays danced across the skies of northern and central Europe, bringing with them strong magnetic disturbances and widespread telegraphic disruptions. These events piqued Birkeland's interests causing him to ask: "Was anything unusual happening on the Sun?" Indeed there was! Solar astronomers had seen large sunspots appear at the eastern limb of the Sun on 2 September, cross the central meridian on 8 September, then disappear behind the western limb on 14 September. On 16 September 1898 Kristian Birkeland wrote a popular article for the newspaper "Verdens Gang" that he called "Sunspots and Northern Light: A Message from the Sun". As mentioned above, the campaign of 1902-1903 was conducted during solar minimum when few sunspots appear on the Sun's surface. Still, Birkeland reported observing magnetic perturbations whose repetition frequency was slightly longer than the equatorial rotation period of the Sun. We now recognize that Birkeland had experienced the two distinct types of magnetic storms whose sources cannot be seen from the ground. Today we would identify the cause of the magnetic storm event of September 1898 as a coronal mass ejection (CME). The repeating storms observed during the winter of 1902-1903 were driven by high-speed streams in the solar wind that flow from coronal holes (Borovsky and Denton, 2006).

CME are explosive, episodic events that are generated when large quantities magnetic flux suddenly emerges from beneath the photosphere within a sunspot. A magnetic bubble and associated plasma rise rapidly through the solar atmosphere, sometimes but not always, generating visible solar flares. If the ejection event occurs near the central meridian of the Sun the CME can reach Earth in about two days. Its effectiveness for generating a large magnetic storm depends on the strength and polarity of the magnetic field in and near the CME. It was not until the 1960s that it was realized that the interplanetary magnetic field acts like a diode gate allowing energy to enter or pass by the magnetosphere (Dungey, 1961). Today the Solar and Heliospheric Observer (SOHO), which is in a halo orbit around the first Lagrange point, monitors solar activity to identify times when CMEs leave the Sun. Recently two satellites, jointly called the Solar Terrestrial Relations Observatory (STEREO) were recently launched into orbits located $47^{\circ}$ ahead and behind the SunEarth line. From these advantages they triangulate CMEs to identify the ones passing close to Earth and warn of approaching magnetic storms.

Coronal holes were first identified as a solar minimum phenomenon during the NASA's Skylab mission in the middle 1970s. They are regions of very low plasma density at coronal altitudes. For this reason the light they emit at soft Xray and extreme ultraviolet wavelengths is very weak in comparison to the rest of the solar disk. Plasma emerges at speeds that are much higher than the average solar wind, along magnetic field lines that point either radially into or out of the coronal hole. At the leading edge of a fast stream, plasma density and magnetic flux tend to pile up into "corotating interaction regions" (CIRs) that excite relatively weak geomagnetic storms in comparison to their CME-driven counterparts (Tsurutani et al., 2006). Here the word "corotating" implies that this solar-wind feature appears in the vicinity of Earth a few days after the coronal-hole source crosses the solar meridian. Since an individual coronal hole can exist for many solar rotations, it generates repeated magnetic storms on Earth. Birkeland correctly identified the effect, but could not have identified the cause. X-ray and ultraviolet radiation coming from the Sun is hidden from ground observers and is mostly absorbed in the protective layers of the upper atmosphere. Once again, we needed access to space to determine just how the Sun causes the repeating storms that occur near solar minimum. If today we are interested in whether a storm is imminent, we need only check $195 \AA$ images of the Sun taken by the Extreme Ultraviolet Imaging Telescope on SOHO. We are blessed to live in times that Kristian Birkeland would certainly have enjoyed.

\section{Conclusions}

Kristian Birkeland published 88 scientific papers; 32 of them appeared in "Comptes Rendus des Sciences", the journal of the French Academy. The others were published in German, Scandinavian and English journals. He also wrote three scientific books. His main treatise "The Norwegian Aurora Polaris Expedition of 1902-1903" fills more than 800 pages in large format. His other two books are about 200 pages in length. Many of Birkeland's insights about the physics of space passed unrecognized until satellites gave us the ability to survey electromagnetic environments beyond our atmosphere. He introduced basic concepts that are central to modern space physics (Lundin, 2002). They include calculations of energetic-particle motions in dipolar magnetic 


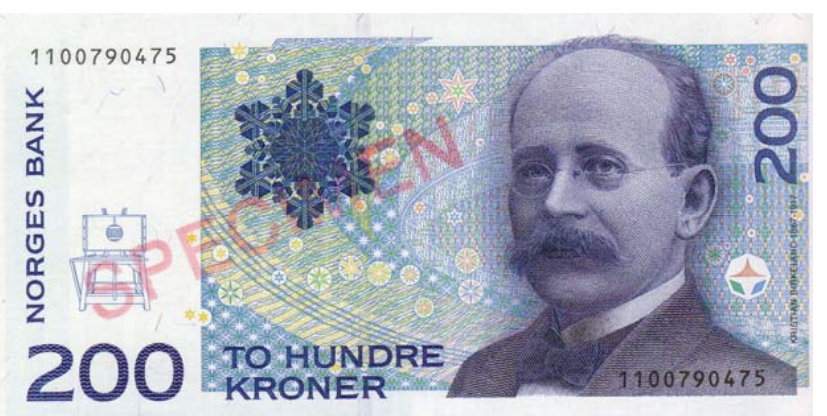

Figure 7. Front side of the Norwegian 200-kroner banknote honoring Birkeland and his research work. To the left Birkeland's terrella experiment is shown. Birkeland is mounted on a background of star patterns, snow crystals and atmosphere.

fields, his description of geomagnetic substorms, and his postulate that electric currents flow along magnetic field lines into and out of the upper atmosphere, today called the Birkeland currents. Birkeland's field-aligned currents have now gained universal acceptance as linking the upper atmosphere to the distant reaches of geospace. He also discovered the global pattern of the electric currents in the polar ionosphere. Based on his own laboratory simulations Birkeland was first to suggest how charged particles from the Sun control geomagnetic disturbances. As space measurements accumulated in the 1970s, attitudes towards Birkeland's work on electric currents in space changed to admiration and acceptance. In retrospect, we recognize that Birkeland's geomagnetic and auroral research, conducted between 1894 and 1913, was decades ahead of its time.

The government of Norway honored Kristian Birkeland as the world's first space physicist. His portrait, along with his terrella experiment and some of his original drawings adorn the Norwegian 200 kroner banknote, first issued in 1994. Birkeland was the first and only Norwegian scientist to be honored by the government in this way. In order to commemorate Birkeland's great achievements in both basic and applied research, in 1986 the University of Oslo, in cooperation with the Norwegian Academy of Science and Letters, and Norsk Hydro inaugurated a continuing series called The Kristian Birkeland Lectures.

Although much of Birkeland's results and ideas were unrecognized or even dismissed for decades, he was vindicated when satellites could fly above the Earth's atmosphere. Interested readers can find a more detailed description of Birkeland's life and works in a recently published biography by Egeland and Burke (2005).

Edited by: K. Schlegel

Reviewed by: B. Hultqvist and G. P. Gregori

\section{References}

Alfvèn, H. and Egeland, A.: Auroral Research in Scandinavia, The Birkeland Lecture No. 1, Norwegian Academy of Science and Letters, Oslo, Norway, 1-32, 1987.

Anderson, B. J., Takahashi, K., and Toth, B. A.: Sensing global Birkeland currents with Iridium engineering magnetometer data, Geophys. Res. Lett., 27, 4045-4058, 2000.

Birkeland, K.: Solution générale des équations de Maxwell pour un milieu absorbant, homogène et isotrope, Comptes Rendus Hebdomadaires des Sèances de l'Acadèmie des Sciences, Paris, T. 12, 1046-1050, 1895.

Birkeland, K.: Résultats des rescherches magnéthiques faites par l'expédition Norvégienne de 1899-1900, Sci. Phy. et Nat., 4éme, T. 12, Geneva, 565-586, 1901.

Birkeland, K.: The Norwegian Aurora Polaris Expedition 19021903, Aschehoug, Christiania, Norway, Vol. I, 1-316, 1908.

Birkeland, K.: The Norwegian Aurora Polaris Expedition 19021903, Aschehoug, Christiania, Norway, Vol. II, 317-801, 1913.

Birkeland, K.: Les rayons corpuscularies du soleil qui pénètrent dans l'athmosphére terrestre sont-ils négatifs ou positives?, Arch. Des Sciences Physiques et Naturelles, 4éme période, T. 41, 22 37 and 108-124, 1916.

Borovsky, J. E. and Denton, M. H.: Differences between CMEdriven storms and CIR driven storms, J. Geophys. Res., 111, A07S08, doi:1029/2005JA011447, 2006.

Bostrøm, R.: Currents in the ionosphere and magnetosphere, in: The Birkeland Symposium on Aurora and Magnetic Storms, edited by: Egeland, A. and Holtet, J. Centre National de la Recherche Scientifique, Paris, 445-459, 1968.

Chapman, S.: Historical introduction to aurora and magnetic storms, in: The Birkeland Symposium on Aurora and Magnetic Storms, edited by: Egeland, A. and Holtet, J., Centre National de la Recherche Scientifique, Paris, 21-29, 1968.

Chapman, S. and Bartels, J.: Geomagnetism, Clarendon Press, Oxford, Vol. I \& II, 1940.

Dessler, A. J.: The evolution of arguments regarding the existence of field-aligned currents, in: Magnetospheric Currents, AGU Geophys. Monograph 28, edited by: Potemra, T., 22-28, 1983.

Dungey, J. W.: Interplanetary magnetic field and the auroral zones, Phys. Rev. Lett., 6, 47-48, 1961.

Egeland, A.: Birkeland's electromagnetic gun, IEEE Trans. Plasma Science, 17, 3-82, 1989.

Egeland, A. and Burke, W. J.: Kristian Birkeland, The First Space Scientist, 1-221, Springer Verlag, 2005.

Fukushima, N.: Equivalence in ground geomagnetic effects of Chapman-Vestine's and Birkeland-Alfvén's electric current systems for polar magnetic storms, Rep. Ionos. Space Res. Japan, 23, 219-228, 1969.

Fukushima, N.: Birkeland's work with geomagnetic disturbances in relation to modern research, The Birkeland Lecture No. 3, Norwegian Academy of Science and Letters, Oslo, 1989.

Gauss, C. F.: Resultate aus den Beobachtungen des magnetischen Vereins Jahre 1836-1841, Werke, 5, 1841.

Iijima, T. and Potemra, T. A.: The amplitude distribution of fieldaligned currents at northern high latitudes observed by TRIAD, J. Geophys. Res., 81, 2165-2174, 1976. 
Iijima, T. and Potemra, T. A.: Large-scale characteristics of fieldaligned currents associated with substorms, J. Geophys. Res., 83, 599-615, 1978.

Lundin, R.: The universal importance of auroral research, in: Egeland Symposium on Auroral and Atmospheric Research, edited by: Moen, J. and Holtet, J., Department of Physics, University of Oslo, 55-75, 2002.

Peratt, A. L.: The legacy of Birkeland's plasma torch, The Birkeland Lecture No. 9, Norwegian Academy of Science and Letters, Oslo, 1996.

Potemra, T. A.: Satellite measurements of the Birkeland currents, The Birkeland Lecture No. 3, Norwegian Academy of Science and Letters, Oslo, 1989.

Schuster, A.: On the origin of magnetic storms, Proc. Roy. Soc. London, 85, 44-50, 1911.
Thomson, J. J.: Cathode rays, Phil. Mag., 44, p. 293, 1897.

Tsurutani, B. T., Gonzalez, W. D., Gonzalez, A. L. C., Guarnieri, F. L., Gopalswamy, N., Grande, M., Kamide, Y., Kasahara, Y., Lu, G., Mann, I., McPherron, R., Soraas, F., and Vasyliunas, V. M.: Corotating solar wind streams and recurrent geomagnetic activity: A review, J. Geophys. Res., 111, A07S01, doi:10.1029/2005JA011273, 2006.

Vasyliunas, V. M.: Mathematical models of magnetospheric convection and coupling to the ionosphere, in: Particles and Fields in the Magnetosphere, edited by: McCormac, B., Reidel, 60-72, 1970.

Vestine, E. H. and Chapman, S.: The electric current-system of geomagnetic disturbances, J. Geophys. Res., 43, 351-382, 1938. 